\title{
Computation and Analysis of High Rocky Slope Safety in a Water Conservancy Project
}

\author{
Meng Yang, ${ }^{1,2}$ Huaizhi Su, ${ }^{1,2}$ and Xiaoqun Yan $^{2}$ \\ ${ }^{1}$ State Key Laboratory of Hydrology-Water Resources and Hydraulic Engineering, Hohai University, Nanjing 210098, China \\ ${ }^{2}$ College of Water Conservancy and Hydropower Engineering, Hohai University, Nanjing 210098, China \\ Correspondence should be addressed to Huaizhi Su; su_huaizhi@hhu.edu.cn
}

Received 11 May 2015; Revised 12 August 2015; Accepted 18 August 2015

Academic Editor: Seenith Sivasundaram

Copyright (c) 2015 Meng Yang et al. This is an open access article distributed under the Creative Commons Attribution License, which permits unrestricted use, distribution, and reproduction in any medium, provided the original work is properly cited.

\begin{abstract}
An integrated method, covering the actual monitoring analysis, practical geological model, and theoretical mathematical simulation model, is systematically proposed and successfully applied. Deformation characteristic of a unique high rocky slope was firstly analyzed from multiple angles and multiple layers by changeable elevations and distances. Arrangements of monitoring points were listed and monitoring equipment was designed to comprise a complete monitoring system. Present larger displacement was concluded for bottom larger displacement caused by water erosion and middle larger displacement formed by seepage. Temporal and spatial displacements rule study of multiple-points linkage effects with water factor proved this conclusion. To better excavate useful message and analyze the deep rule from the practical monitoring data, the slope geological model was conducted and rock mechanic parameters were researched. Finally, a unique three-dimensional finite element model was applied to approach the structure character using numerical simulations. The corresponding strength criterion was used to determine the safety coefficient by selecting a typical section. Subsequently, an integrated three-dimensional finite element model of the slope and dam was developed and more detailed deformation evolution mechanism was revealed. This study is expected to provide a powerful and systematic method to analyze very high, important, and dangerous slopes.
\end{abstract}

\section{Introduction}

Since 1949, China has constructed approximately 85,000 dams, especially for huge hydropower projects, such as Sanxia, Xiaowan, Jinping, Tian Shengqiao, Xiluodu, Longtan, and Shuangjiangkou, which made China the largest hydropower producer of developing nations worldwide. It also has resulted in many high slope problems [1]. The study of a high slope has become very popular in the geotechnical engineering field [2-4]. Mathematical methods, such as neural network and time series, became a popular way to analyze the monitoring data (see Babapour et al. [5], Abdalla et al. [6], Zevallos and Hotta [7], Vinoth et al. [8], and the references therein). The finite element method (FEM) of numerical simulation technology was also widely used for geotechnical engineering (see Chang et al. [9], Alemdag et al. [10], and Vasilev et al. [11]). However, the monitoring research of a slope is the most important aspect before the above analysis from Goodman and Kieffer [12]. Because the inspection data at original space position of a slope can really reflect the slope behavior and they were vitally important when evaluating the safety and forecasting the deformation tendency from the views of Peng et al. [13] and Rott et al. [14], many studies mainly focused on indoor test, single mathematical method analysis, single engineering geological research, or single practical monitoring analysis (see Morse et al. [15] and Zhao et al. [16]). It is very meaningful to develop an integrated method to more comprehensively and objectively study and analyze the deformation mechanism of the slope $[17,18]$.

On the other hand, it is a unique high rocky slope in the world with $700 \mathrm{~m}$ height from the river as the Yellow River upstream hydropower station with $250 \mathrm{~m}$ height is the largest hydropower station, installed capacity, and power generation capacity in the Yellow River. The unique position, engineering background, and complex outside environment give the particular characteristic different from the present existing slope. Thereby, a subsequent question, the displacement, and evolution rule of this unique slope under this special slope 


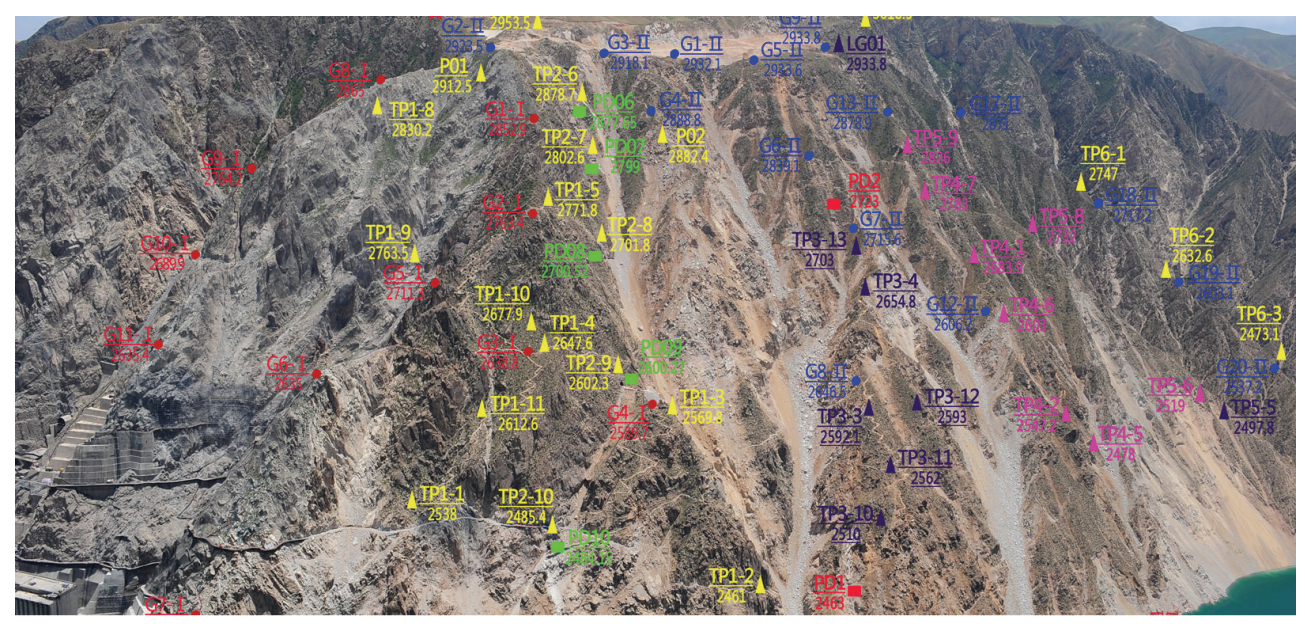

FIGURE 1: Arrangement of the surface points.

background are needed to be badly solved. The consequent question is how to analyze the above problem and whether the FEM and other analyses methods are still suitable and what the analyses results are through these methods. It is also very important to obtain the original monitoring message and construct the analysis process by the above methods. Therefore, the analysis process and idea are different from the common slope problem. The unique slope decided the analysis and calculation processes are also unique.

Thus, this paper firstly focuses on the 1:1 model test together with the multiple-source information of the specific and enormous high rocky slope in the Yellow River upstream hydropower project. The deformation behavior was analyzed for multiple aspects and multiple levels. To fully extract and analyze the original model data, the actual monitoring analysis, the slope geological model, and rock mechanic parameters were introduced. To further reflect the deformation rule and obtain final conclusion supported by practical monitoring data, a three-dimensional finite element model of the slope and dam was applied to approach the structure character using numerical simulations [19, 20]. Firstly, the Drucker-Prager (D-P) criterion was used to determine the safety coefficient by the finite element model and a program for automatically obtaining the strength reduction coefficient was developed in the ANSYS parametric design language (APDL). Secondly, the whole deformation law of slope and dam was also analyzed by a generalized three-dimensional finite element model.

\section{Arrangement of Monitoring Points}

The Yellow River upstream hydropower project is the second largest step electric station from Longyang Gorge to Qingtong Gorge in the upper reach of the Yellow River. The slope of Kuipa is at the right upstream of the Yellow River. The altitude of the top platform of the slope is $2930 \mathrm{~m}-2950 \mathrm{~m}$, and it is $750 \mathrm{~m}$ long and $50 \mathrm{~m} \sim 290 \mathrm{~m}$ wide with an area of $115,000 \mathrm{~m}^{2}$. Deformation monitoring is the main content and the monitoring points were listed in each section. The arrangement of the surface points and monitoring system were, respectively, shown in Figures 1 and 2.

From Figures 1 and 2, it can be concluded that the slope deformation was monitored for surface and deep aspects by using all kinds of equipment. The surface points were the easiest to be obtained and the amount could be directly used to reflect the whole slope deformation state. To finish the complete monitoring analysis, a system monitoring measure was necessary and designed in Figure 2.

\section{Deformation Analysis of Original Model Monitoring}

By using the monitoring equipment, all kinds of deformation information were finally obtained. The surface point distribution was shown in Figure 1. After observing and analyzing the monitoring data, representative points were listed and analyzed in Figure 3 and Table 1 . These points were selected from downstream to upstream by four elevation levels, $2900 \mathrm{~m}, 2800 \mathrm{~m}, 2600 \mathrm{~m}$, and $2500 \mathrm{~m}$. Slope whole deformation was small and stable under the original water level. However, larger amount was caused by changeable water level after building the Yellow River upstream hydropower project. Therefore, the water factor should not be ignored in any analysis and calculation. Therefore, the water level was particularly added with cumulative displacement velocity in Figure 3.

From Figure 3, it can be known that the deformation velocity is larger in middle areas and smaller deformation velocity was in both sides from downstream to upstream for all the height levels. The deformation velocity amount downstream was smaller than the one upstream. The whole deformation velocity tendency was that velocity amount became smaller and more stable as the water level rose steadily. The process of building the dam between the slopes should influence downstream more than upstream of the slope because the excavation, blast, and other construction procedures were carried out near downstream. However, the hypothesis was wrong to the practical state. It was also 
TABLE 1: Monitored points to different heights from downstream to upstream.

\begin{tabular}{lccccccccc}
\hline Points noted & Height $(\mathrm{m})$ & Points name & Height $(\mathrm{m})$ & Points noted & Height $(\mathrm{m})$ & Points noted & Height $(\mathrm{m})$ & Points noted & Up to down $(\mathrm{m})$ \\
\hline G2-II & 2923.5 & G8-I & 2865.0 & G10-I & 2689.9 & G4-I & 2589.7 & G6-II & 2839.1 \\
G3-II & 2918.1 & G1-I & 2852.9 & TP1-10 & 2677.9 & TP1-3 & 2569.8 & TP3-4 & 2654.8 \\
G1-II & 2932.1 & G4-II & 2888.8 & TP3-4 & 2654.8 & TP3-3 & 2592.1 & TP3-11 & 2562.0 \\
LG01 & 2933.8 & $/$ & $/$ & TP4-1 & 2683.9 & TP3-12 & 2593 & TP1-2 & 2461.0 \\
$/$ & $/$ & $/$ & $/$ & $/$ & $/$ & TP4-2 & 2547.2 & $/$ & $/$ \\
\hline
\end{tabular}

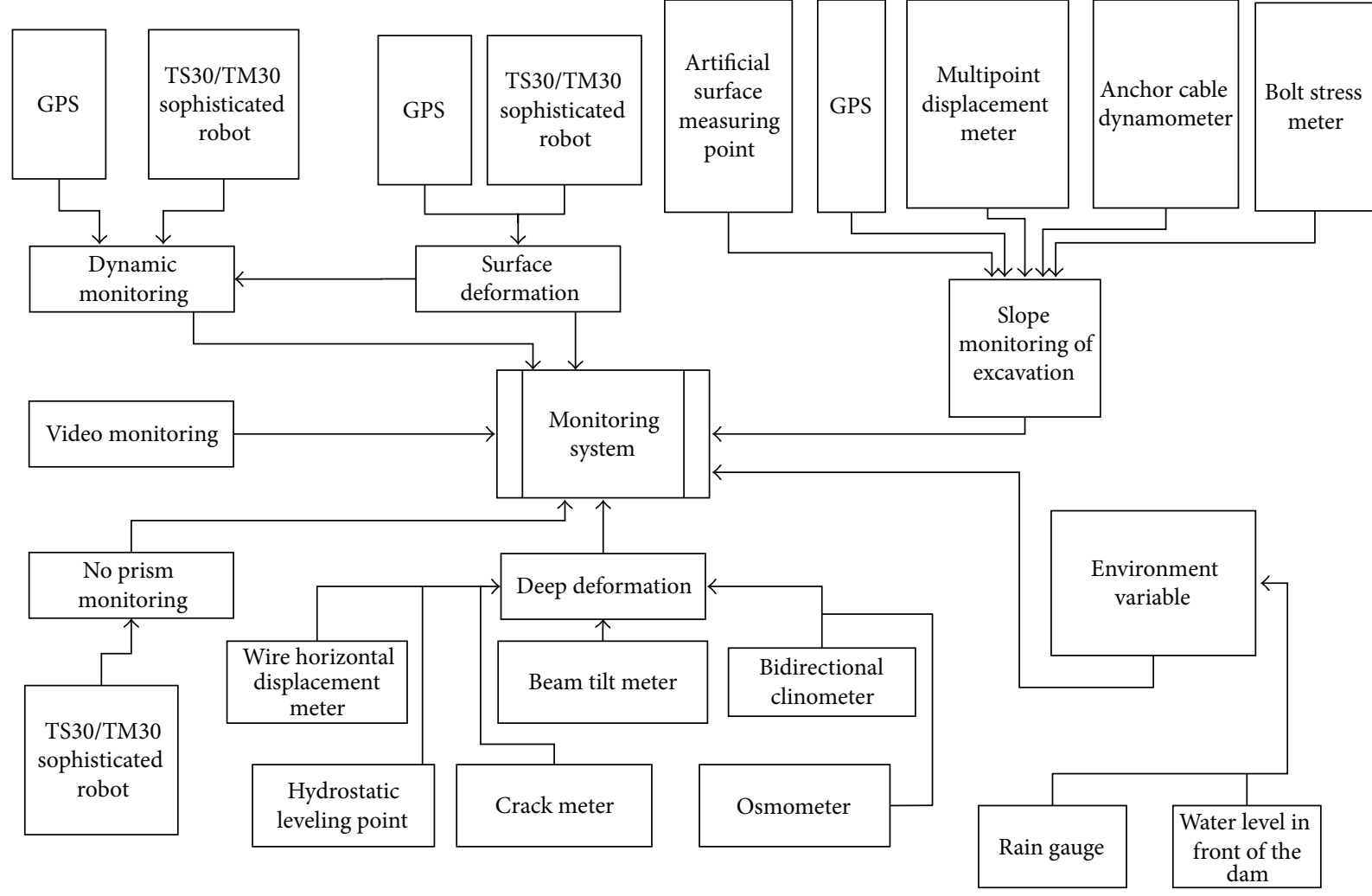

FIGURE 2: Constitution sketch of monitoring system.

shown that the slope was safe when the dam was built and its deformation changed greatly with the increasing of cumulative water. Therefore, the new conclusion was that seepage channels were formed under high water pressure and the deformation was caused by the inner loose rock soaked by the seepage water. The surface rock larger deformation was formed for locking the binding force of upper rock.

From Figure 3, the main deformation area happened in the middle of the slope. To further explore the slope deformation law, middle part deformation velocity of the slope was separately listed from $2840 \mathrm{~m}$ to $2460 \mathrm{~m}$ in Figure 4. With the mutual comparisons among these monitoring points, the displacement velocity of around $2650 \mathrm{~m}$ altitude was larger and the one of $2455 \mathrm{~m}$ altitude near the bottom area was smaller. Based on the above analyses, the conclusion can be further gotten that the seepage channel might be formed in the middle of the slope with the water level of the river growing from $2390 \mathrm{~m}$ to $2455 \mathrm{~m}$ and the outside water pressure pulled the water inside to form many channels up and down. That may be the reason for present large deformation.

To analyze the geological model of the slope, the practical engineering geological survey and rock mechanics characteristic test were conducted. Thus, the geological model of the slope was built based on the engineering geological type and property, structural characteristics of rock mass, and the rock mass geological evaluation. A field geological survey was finished by drilling in different altitudes. The drilling measuring point of $2500 \mathrm{~m}$ elevation, DR05, was exampled in Figure 5.

The drilling depth of DR05 is $150 \mathrm{~m}$ and camera depth is $144.6 \mathrm{~m}$. In the test section, there are 136 cracks (25 are closed) mainly in the hole with depth of $70 \mathrm{~m} \sim 71.5 \mathrm{~m}$. From the results of acoustic wave detection, there is a low velocity section in the 145.8 146.8 m, which is inferred as a fault. After a systematic geological survey of different drilling depths for different drilling points, the engineering geological type and property and the rock mass geological evaluation are 


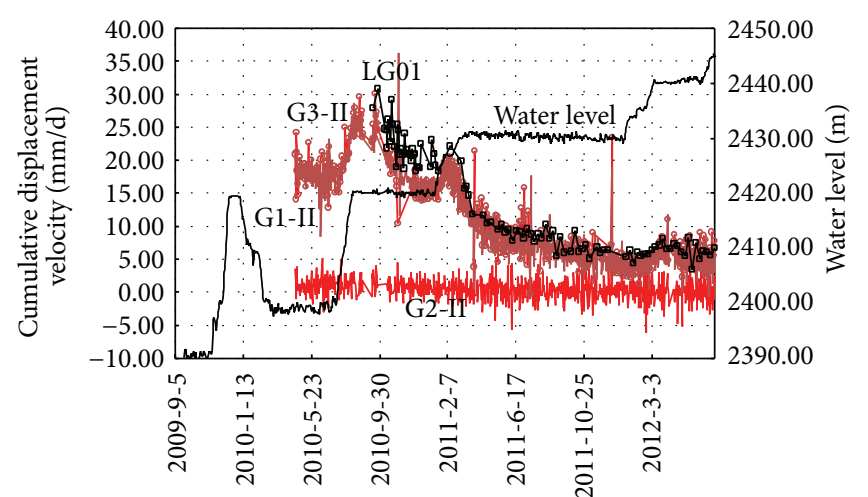

2900 m elevation

$$
\begin{aligned}
- \text { G2-II } & \rightarrow \text { LG01 } \\
\rightarrow \text { G3-II } & - \text { Water level }
\end{aligned}
$$

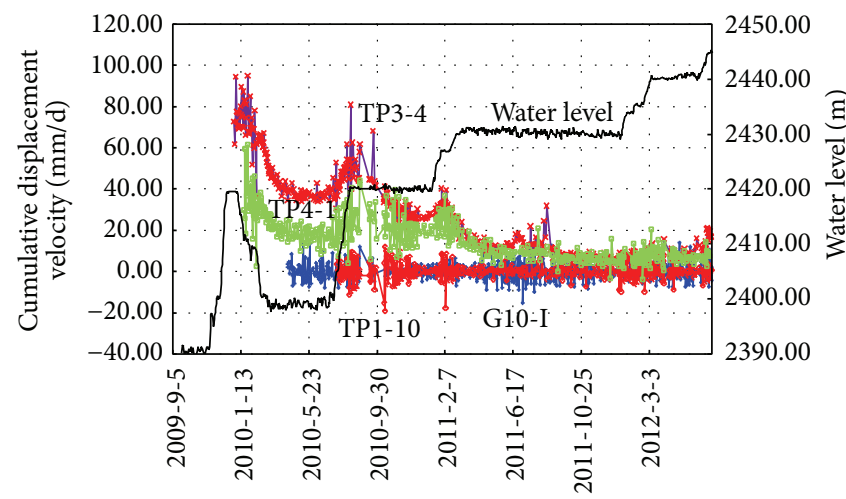

2600 m elevation

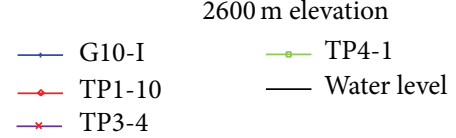

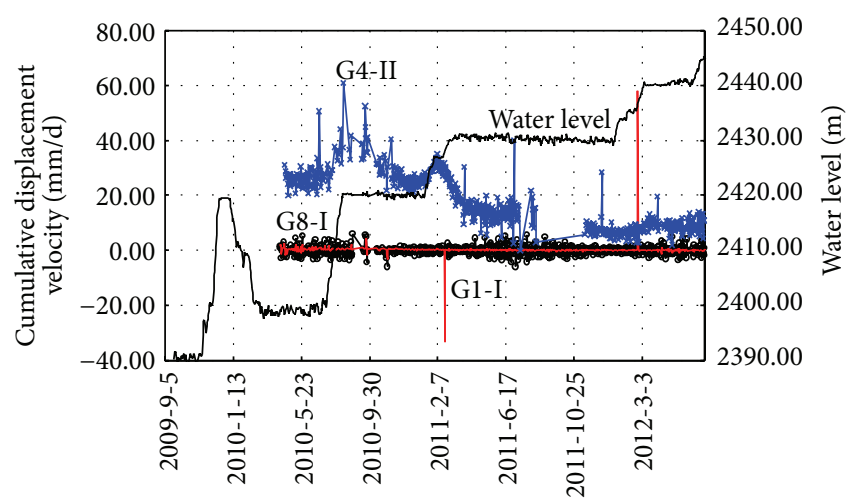

2800 m elevation
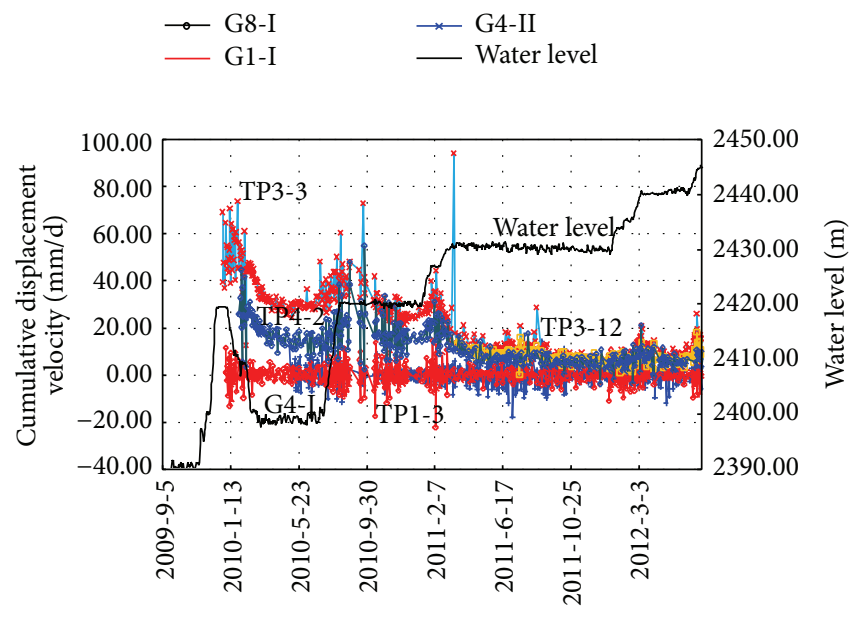

2500 m elevation

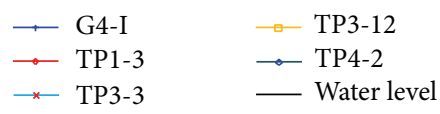

FIGURE 3: Points monitored from downstream to upstream of the slope for different elevations.

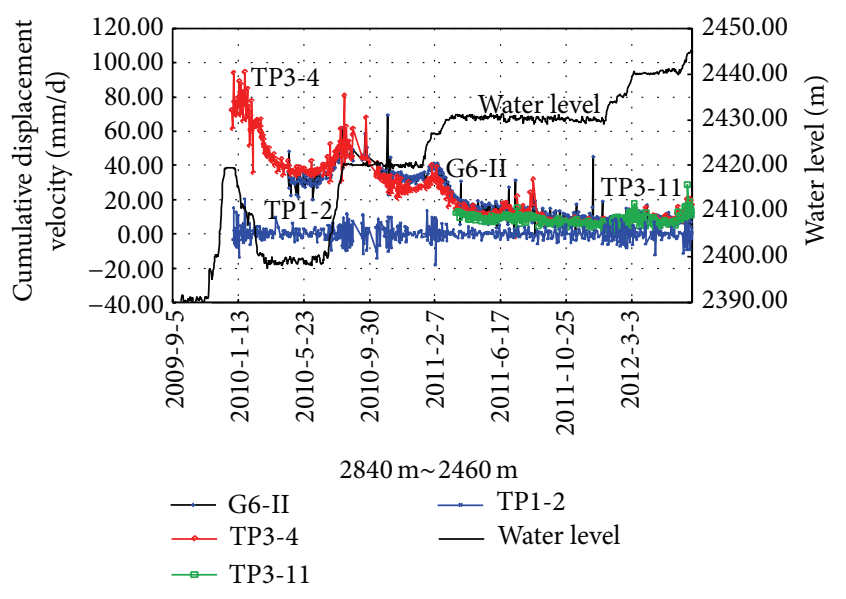

FIGURE 4: The displacement rule for different points of different elevations.

obtained and the final slope geological model is presented in Table 2. The slope geological model is the evaluation base for the rock mass quality and it is also used to interpret actual data on the base of monitoring data.

\section{Analysis of the Rock Mechanic Parameters}

The rock mechanic parameters are critical aspects for so high rocky slope safety analyses. To reveal the rock mechanic parameters, the sonic technique is applied to detect the wave velocity of structural rock mass. The wave velocities of granular structure, fragmentation structure, and block structure are, respectively, less than $2200 \mathrm{~m} / \mathrm{s}$, less than $2750 \mathrm{~m} / \mathrm{s}$, and more than $3300 \mathrm{~m} / \mathrm{s}$. Based on the above wave velocities calculations and the analogy analyses of rock mechanics test results of dam site area, the rock mechanic parameters are described to explain the methodology to get such parameters and the reliability in Table 3.

In future, the slope safety is strongly influenced by the water permeability and the rule detection of the permeability is also a key point for analyzing the rock mechanic parameters and explaining the methodology to get such parameters and the reliability. Water permeability of the rock mass 
TABLE 2: Slope geological model for rock mass.

\begin{tabular}{llll}
\hline Order & Grading standard & Geological type and property & Geological evaluation \\
\hline I & $\begin{array}{l}\text { Fault with greater than } 1000 \mathrm{~m} \\
\text { extension length and greater than } \\
0.5 \mathrm{~m} \text { broken band width }\end{array}$ & $\begin{array}{l}\text { Weak structure plane; } \\
\text { continuous distribution } \\
\text { throughout the bank and both } \\
\text { sides }\end{array}$ & $\begin{array}{l}\text { It controlled the boundary of the } \\
\text { whole slope stability }\end{array}$ \\
\hline II & $\begin{array}{l}\text { Weak structural plane; } \\
\text { and } 0.2 \sim 0.5 \mathrm{~m} \text { broken band } \\
\text { width }\end{array}$ & not completely cutting the slope & $\begin{array}{l}\text { It controlled the potential weak } \\
\text { surface; } \\
\text { weak surface affected rock } \\
\text { strength and deformation }\end{array}$ \\
\hline III & $\begin{array}{l}\text { Fault and the growing crack with } \\
\text { less than } 100 \text { m extension length } \\
\text { and less than } 0.5 \mathrm{~m} \text { broken zone } \\
\text { width }\end{array}$ & $\begin{array}{l}\text { Rigid structural plane; } \\
\text { fault filled with rock fragments } \\
\text { and breccias; } \\
\text { crack filled with calcite }\end{array}$ & $\begin{array}{l}\text { It influenced the integrity and the } \\
\text { overall strength of the rock mass }\end{array}$ \\
\hline
\end{tabular}

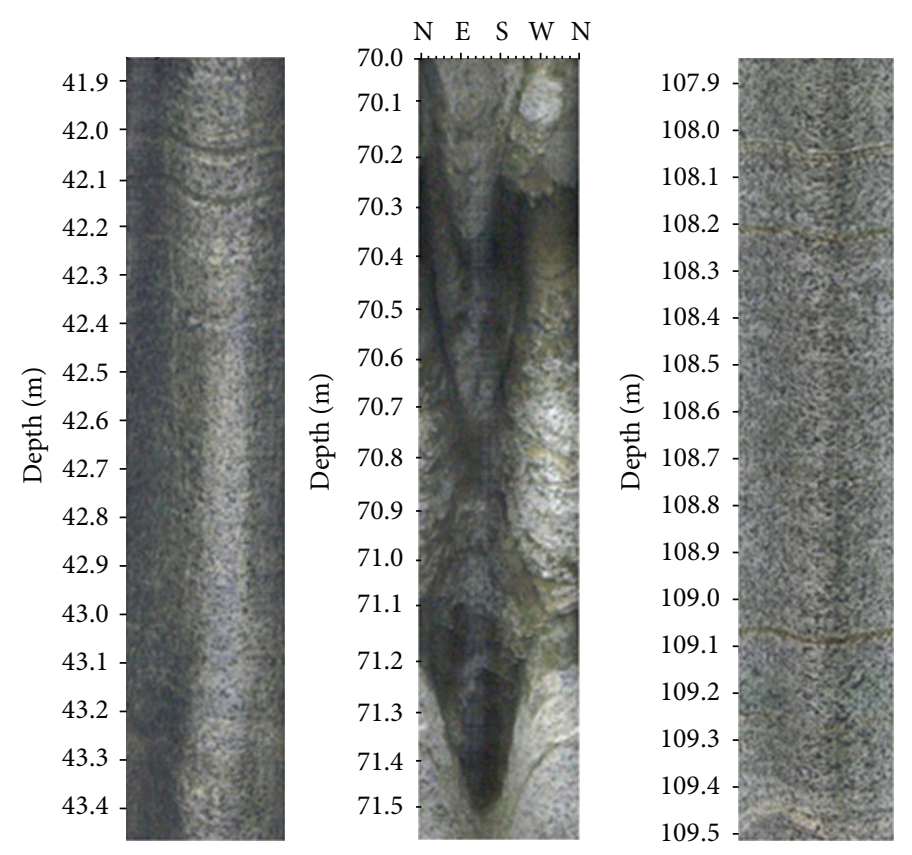

FIGURE 5: Rock structure characteristics in different drilling depths.

with the deformation zone is strong. The parameters of the permeability are as follows: granular structure is over $70 \mathrm{~m} / \mathrm{d}$, the fragmentation structure is $30 \sim 70 \mathrm{~m} / \mathrm{d}$, and block structure is $10 \sim 30 \mathrm{~m} / \mathrm{d}$.

\section{Determination of the Safety Factor for the Slope}

A slope is inevitable during construction of water conservancy engineering projects. The stability of the slope seriously affects the safety of construction and operation. How the sliding swell of the dam affected electrical equipment and accumulated landslides close to the dam were serious concerns; it is necessary to analyze the slope stability. The deformation forms of the slope mainly contain relaxation tensile fracture, slide, collapse, dumping, peristalsis, and flow. The mechanical property parameters, geometric dimensions, and external loads are the main factors that influence the slope stability (see Yin [21] and Zhang et al. [22]).

There are two common methods for analyzing the slope stability: the limit equilibrium method and numerical analysis method. The first method is to divide a landslide into several vertical strips to calculate the safety coefficient by balancing the equation of forces established by the MohrCoulomb shear strength theory. The second method overcomes the shortcoming of the former method, which neglects the stress-strain relationship of the soil. The FEM is the earliest and the most widely used numerical analysis method [23].

The instabilities of many slopes are often caused by an intensity reduction of the external environment, such as the Kuipa slope in the above analysis. Therefore, this method for determining the safety factor is consistent with the actual condition. The basic idea of strength reduction of the FEM is that an initial reduction coefficient is set up, and the strength 
TABLE 3: Rock mechanic parameters of different rock structures.

\begin{tabular}{|c|c|c|c|c|c|c|}
\hline \multirow{2}{*}{ Structure type } & \multirow{2}{*}{$\begin{array}{c}\text { Compressive } \\
\text { strength (MPa) }\end{array}$} & \multirow{2}{*}{$\begin{array}{l}\text { Deformation } \\
\text { modulus (GPa) }\end{array}$} & \multicolumn{2}{|c|}{ Rock mass shear (break) parameters } & \multirow{2}{*}{ Poisson's ratio } & \multirow{2}{*}{ Unit weight $\left(\mathrm{g} / \mathrm{cm}^{3}\right)$} \\
\hline & & & $f^{\prime}$ & $C^{\prime}(\mathrm{MPa})$ & & \\
\hline $\begin{array}{l}\text { Granular } \\
\text { structure }\end{array}$ & $<22$ & $0.1 \sim 0.45$ & $0.35 \sim 0.55$ & $0.04 \sim 0.06$ & $0.42 \sim 0.48$ & $<2.35$ \\
\hline $\begin{array}{l}\text { Fragmentation } \\
\text { structure }\end{array}$ & $22 \sim 55$ & $0.45 \sim 1.2$ & $0.57 \sim 0.68$ & $0.17 \sim 0.43$ & $0.34 \sim 0.42$ & $2.42-2.63$ \\
\hline Block structure & $55 \sim 85$ & $1.3 \sim 3.7$ & $0.72 \sim 0.83$ & $0.52 \sim 0.63$ & $0.33 \sim 0.36$ & $2.63-2.71$ \\
\hline Country rock & $105 \sim 110$ & $12 \sim 16$ & $1.03 \sim 1.21$ & $1.35 \sim 1.57$ & $<0.26$ & 2.71 \\
\hline
\end{tabular}

parameters are reduced. Then, a FEM calculation with the reduction parameters is performed. If the result is convergent, the slope would be stable. The calculation is repeated until the result is barely nonconvergent. This is the upper-level value for the safety coefficient. Slope stability refers to the slope strength, so selection of the strength criterion is very important. Coulomb established the Coulomb formula of shear strength based on the relationship between the shear strength of the geotechnical material and normal stress on the failure surface. The formula is

$$
\tau_{f}=c-\sigma \tan \varphi
$$

where $\tau_{f}$ is for the shear strength of the damaged section; $\sigma$ is the normal stress of the damaged section; and $c$ and $\varphi$ are the cohesive force and internal friction angle, respectively.

According to Moore's law, formula (1) can be generalized to the plane stress state:

$$
\begin{aligned}
\frac{\sigma_{1}-\sigma_{3}}{2 c \cot \varphi-\left(\sigma_{1}+\sigma_{3}\right)} & =\sin \varphi, \\
\frac{1}{2}\left(\sigma_{1}-\sigma_{3}\right) & =c \cos \varphi-\frac{1}{2}\left(\sigma_{1}+\sigma_{3}\right) \sin \varphi .
\end{aligned}
$$
C).

This is called the Mohr-Coulomb strength criterion (M-

In practice, the $\mathrm{M}-\mathrm{C}$ is an irregular hexagon in the $\pi$ plane. It is an equilateral hexagon for a special situation called the Tresca criterion:

$$
\begin{aligned}
& F=\sqrt{J_{2}} \cos \theta_{\sigma}-C=\sqrt{J_{2}} \cos \theta_{\sigma}-k, \quad \theta_{\sigma}=0, \\
& F=\sqrt{J_{2}}-C=\sqrt{J_{2}}-k .
\end{aligned}
$$

The function is called von Mises strength criterion.

Since $\theta_{\sigma}$ is constant, the yield function is not associated with $\theta_{\sigma}$ and the third invariant $\sqrt{J_{3}}$. Therefore, it is a circle in the $\pi$ plane and can be expressed as follows:

$$
F=\alpha I_{1}+\sqrt{J_{2}}-k=0
$$

This is the generalized von Mises strength criterion, as shown in Figure 6.

In geotechnical engineering, Drucker-Prager took the effect of the hydrostatic pressure on the plastic behavior of the rock mass and the average stress $\sigma_{m}$ or $I_{1}$ into consideration

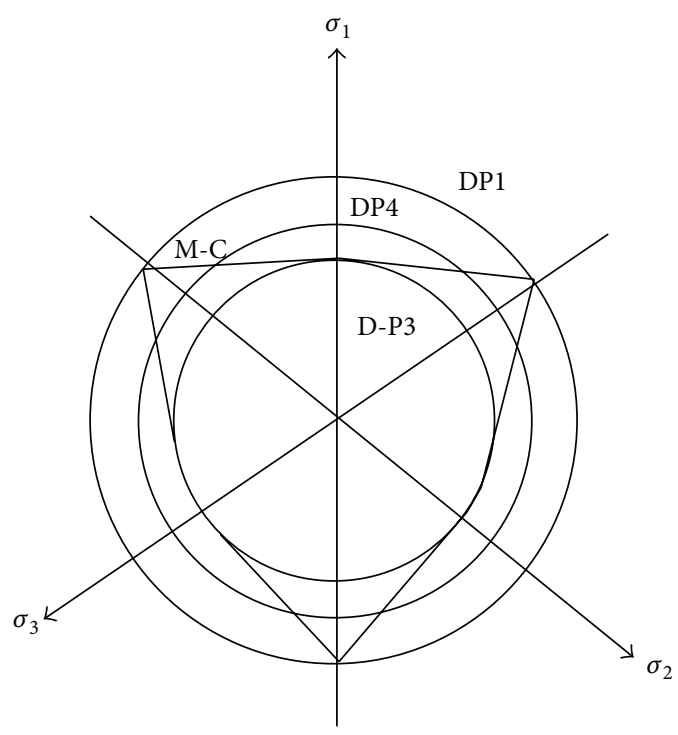

FIGURE 6: D-P strength curve in the $\pi$ plane.

under the plane strain condition and then generalized the von Mises criteria as follows:

$$
\begin{aligned}
& F=\alpha I_{1}+\sqrt{J_{2}}-k=0, \\
& \alpha=\frac{\sin \varphi}{\sqrt{3\left(3+\sin ^{2} \varphi\right)}}, \\
& k=\frac{3 c \cos \varphi}{\sqrt{3\left(3+\sin ^{2} \varphi\right)}} .
\end{aligned}
$$

Different expressions of $\alpha$ and $k$ will be calculated for different conditions. Compression failure will appear as the value of $\theta_{\sigma}$ is $\pi / 6$ :

$$
\begin{aligned}
& \alpha=\frac{2 \sin \varphi}{\sqrt{3(3-\sin \varphi)}}, \\
& k=\frac{6 c \cos \varphi}{\sqrt{3}(3-\sin \varphi)} .
\end{aligned}
$$

The yield curve in the $\pi$ plane is a circumcircle of corner points of an unequal angle hexagon, which is the D$\mathrm{P}$ criterion of the corner point circumcircle, generally called 
TABLE 4: Rock material parameters of the DP3 criterion.

\begin{tabular}{lcccccc}
\hline Structure type & $\begin{array}{c}\text { Compression } \\
\text { strength }(\mathrm{MPa})\end{array}$ & $\begin{array}{c}\text { Deformation } \\
\text { modulus }(\mathrm{GPa})\end{array}$ & $\begin{array}{c}\text { Rock shear parameters } \\
\varphi_{1}\end{array}$ & $C^{\prime}(\mathrm{MPa})$ & Poisson's ratio & Unit weight $\left(\mathrm{g} / \mathrm{cm}^{3}\right)$ \\
\hline $\begin{array}{l}\text { Cataclastic } \\
\text { texture }\end{array}$ & 40 & 0.8 & $\begin{array}{c}0.625 \\
\left(32.00^{\circ}\right)\end{array}$ & 0.30 & 0.375 & 2.5 \\
Block fractured & 75 & 1.3 & $\begin{array}{c}0.75 \\
\left(36.87^{\circ}\right)\end{array}$ & 0.55 & 0.335 & 2.65 \\
Basis & 105 & 2 & $\begin{array}{c}1.15 \\
\left(48.99^{\circ}\right)\end{array}$ & 1.35 & 0.220 & 2.71 \\
\hline
\end{tabular}

TABLE 5: Rock material parameters transferred from the DP3 to DP1 criterion.

\begin{tabular}{lcccccc}
\hline Structure type & $\begin{array}{c}\text { Compression } \\
\text { strength }(\mathrm{MPa})\end{array}$ & $\begin{array}{c}\text { Deformation } \\
\text { modulus }(\mathrm{GPa})\end{array}$ & \multicolumn{2}{c}{ Rock shear parameters } & Poisson's ratio & Unit weight $\left(\mathrm{g} / \mathrm{cm}^{3}\right)$ \\
\hline Cataclastic texture & 40 & 0.8 & 22.5121 & 0.1997 & 0.375 & 2.5 \\
Block fractured & 75 & 1.3 & 24.9565 & 0.03413 & 0.335 & 2.65 \\
Basis & 105 & 2.0 & 29.9594 & 0.06767 & 0.220 & 2.71 \\
\hline
\end{tabular}

DP1 criteria. Reference [24] concluded that a great difference was found between the traditional M-C strength criterion and DP1 criteria. The authors suggested that the Mohr-Coulomb matching criterion under the plane strain associated flow rule and the nonassociated flow rule matching with plane strain should be adopted for the plane strain condition $[25,26]$. The formulas of the above two criteria are

$$
\begin{gathered}
\alpha=\frac{\sin \varphi}{\sqrt{3\left(3+\sin ^{2} \varphi\right)}}, \\
k=\frac{3 c \cos \varphi}{\sqrt{3\left(3+\sin ^{2} \varphi\right)}}, \\
\left(\theta_{\sigma}=-\frac{\sin \varphi}{\sqrt{3}}\right),
\end{gathered}
$$

which is recorded as the DP3 criterion and its dilatation angle, $\phi$, is 0 . Consider

$$
\begin{gathered}
\alpha=\frac{2 \sin \varphi}{3}, \\
k=c \cos \varphi, \\
\left(\theta_{\sigma}=0\right),
\end{gathered}
$$

which is recorded as the DP4 criterion and its dilatation angle, $\phi$, is equal to $\varphi$.

For a three-dimensional finite element model, the DP5 criterion can be used and the expression is as follows:

$$
\begin{aligned}
& \alpha=\frac{2 \sqrt{3} \sin \varphi}{\sqrt{2} \sqrt{3 \pi\left(9-\sin ^{2} \varphi\right)}}, \\
& k=\frac{6 \sqrt{3} \cos \varphi}{\sqrt{2} \sqrt{3 \pi\left(9-\sin ^{2} \varphi\right)}} .
\end{aligned}
$$

The related finite element software can be utilized by calculating the corresponding values of $c$ and $\varphi$, which are transferred into the DP1 criterion with the equivalent of $\alpha$ and $k$ between the DP3 or DP4 and DP1.

To simulate the deformation status of the Kuipa slope at the present stage, a finite element software program is used. The basic geometric size is the altitude of $2930 \mathrm{~m}-2950 \mathrm{~m}$ and width of $50 \mathrm{~m}-290 \mathrm{~m}$. Material parameters are shown in Tables 4 and 5 for DP3. $c$ and $\varphi$ of DP3 are transferred to the ones for the DP1 criterion:

$$
\begin{aligned}
& \alpha=\frac{2 \sin \varphi_{1}}{\sqrt{3}\left(3-\sin \varphi_{1}\right)}, \\
& k=\frac{6 c_{1} \cos \varphi_{1}}{\sqrt{3}\left(3-\sin \varphi_{1}\right)},
\end{aligned}
$$

which is called the DP1 criterion; consider

$$
\begin{aligned}
& \alpha=\frac{\sin \varphi}{\sqrt{3\left(3+\sin ^{2} \varphi\right)}}, \\
& k=\frac{3 c \cos \varphi}{\sqrt{3\left(3+\sin ^{2} \varphi\right)}},
\end{aligned}
$$

which is named the DP3 criterion; consider

$$
\begin{gathered}
\alpha=\frac{2 \sin \varphi}{3}, \\
k=c \cos \varphi \\
\left(\theta_{\sigma}=0\right),
\end{gathered}
$$

which is the DP4 criterion.

The whole three-dimensional finite element model is shown in Figure 7. To be consistent with the previous analysis, the finite element model of the cross section of QC10 was extracted and is shown in Figure 8. Water level changes from 


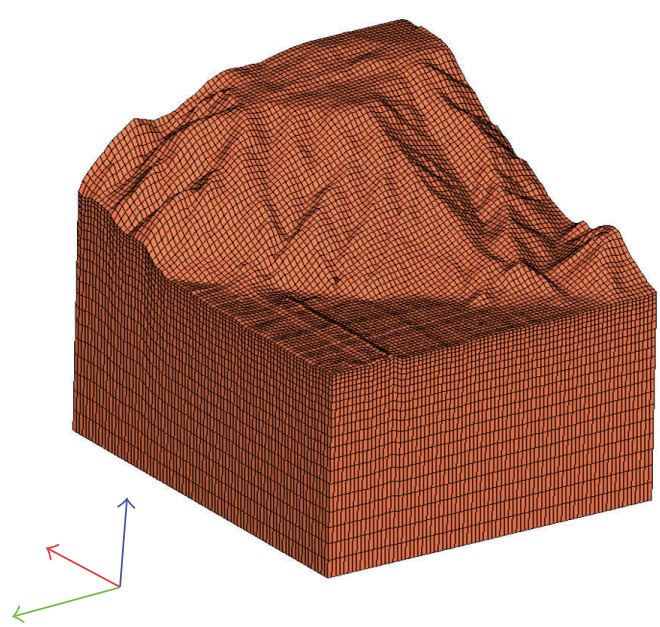

Figure 7: Three-dimensional finite element model of the whole slope.

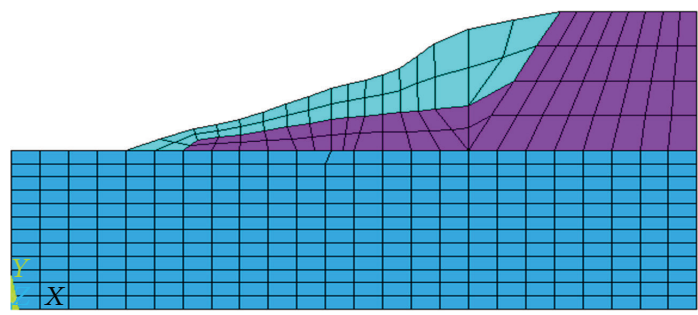

FIGURE 8: The finite element model of QC10 section.

$2260 \mathrm{~m}$ to $2448 \mathrm{~m}$ and the influences of water pressure were considered. The material parameter table and DP3 strength criterion were used.

From the results of Figures 9 and 10, the plasticity area matches the real situation. The material parameters have the aging character, which changes all the time under the external forces and reflects the deformation behavior during that time. From all the available data, the comprehensive displacement calculated by this method is consistent with the actual measurement result.

Based on the basic idea of the strength reduction method, a program for automatically obtaining the strength reduction coefficient is developed in the ANSYS parametric design language (APDL). The result is shown in Figure 11. The program improves the calculating efficiency and accuracy.

The relationship between the safety coefficient and sediment value for QC10 can be calculated by the developed program, which is shown in Figure 12. The FEM calculation result is emanative as the reduction value is 1.249 . Thereby, the final safety coefficient is 1.248 .

\section{Analysis of the Finite Element Model}

A general three-dimensional finite element model of the slope and dam was set up, and the influence of the water level was further investigated [27]. The model is shown in Figure 13. Material parameters are listed in Table 6.

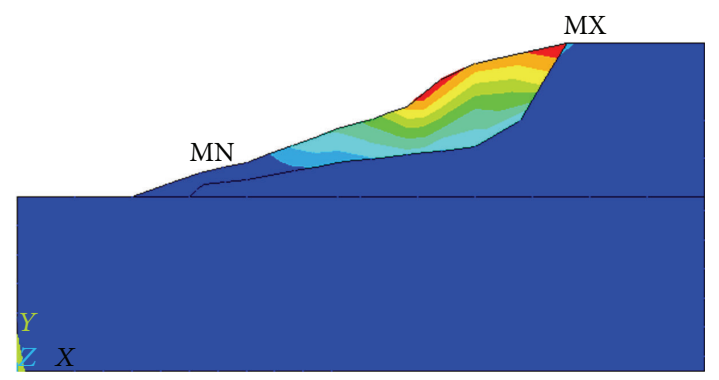

FIgURE 9: Scattergram of the equivalent plastic strain of the QC10 section.

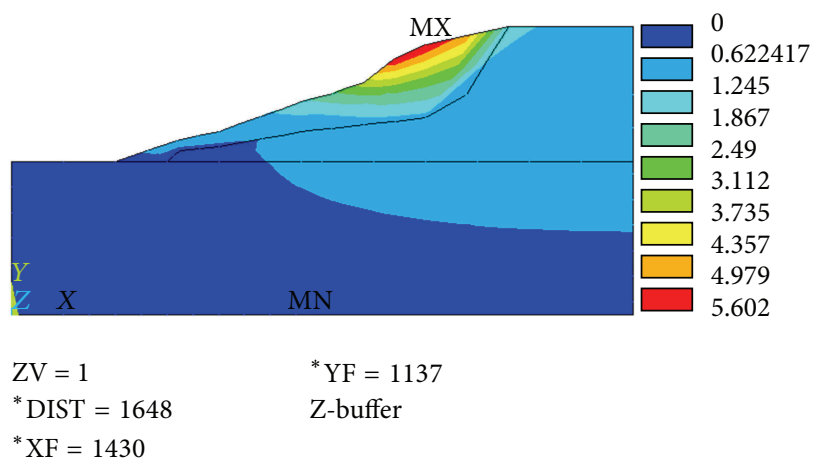

FIGURE 10: Comprehensive displacement nephogram of the QC10 section.

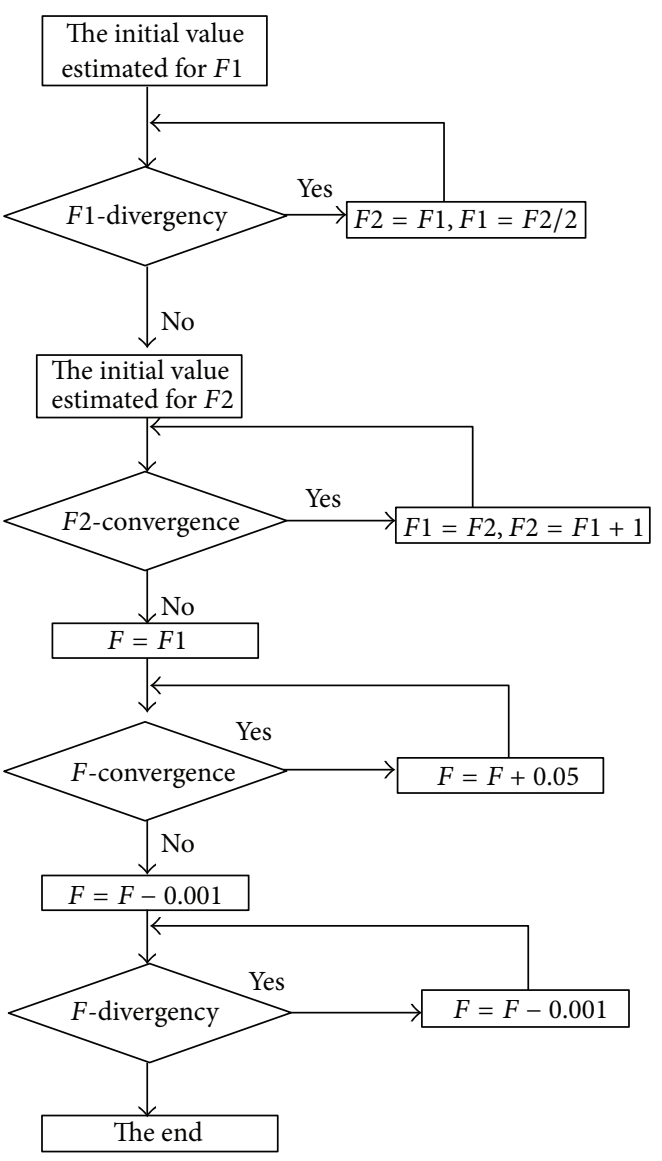

FIGURE 11: Process of determining the strength reduction coefficient. 
TABLE 6: Material parameters.

\begin{tabular}{lcccccc}
\hline Structure type & $\begin{array}{c}\text { Compression } \\
\text { strength }(\mathrm{MPa})\end{array}$ & $\begin{array}{c}\text { Deformation } \\
\text { modulus }(\mathrm{GPa})\end{array}$ & \multicolumn{2}{c}{ Rock shear parameters } & Poisson's ratio & Unit weight $\left(\mathrm{g} / \mathrm{cm}^{3}\right)$ \\
\hline Exterior margin & 40 & 0.75 & 22.51 & 0.1997 & 0.38 & 2.50 \\
Trailing edge & 75 & 1.3 & 24.96 & 0.034 & 0.34 & 2.65 \\
Basis & 10 & 2.0 & 29.96 & 0.068 & 0.22 & 2.71 \\
Dam body & $/$ & $\begin{array}{c}22 \text { (elastic } \\
\text { modulus) }\end{array}$ & $/$ & $/$ & 0.17 & 2.41 \\
\hline
\end{tabular}

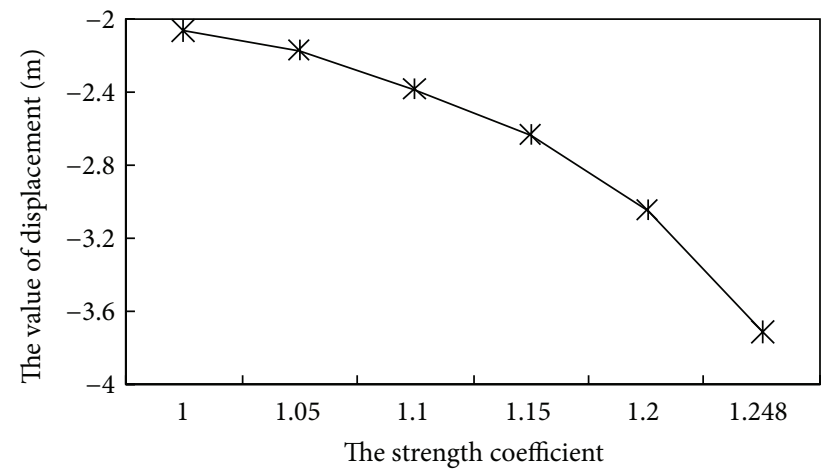

FIGURE 12: Relationship between the sediment and reduction coefficient on the node of QC10.

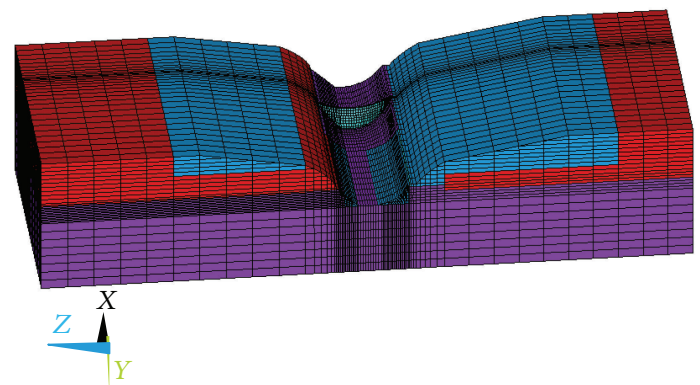

FIGURE 13: Generalized three-dimensional finite element model of the slope and arch dam.

Four main areas are considered. The effects of the water pressure acting on the slope and dam are considered separately. The calculation results are shown in Figures 14 and 15. The height of the slope is very high, and the water level is only $188 \mathrm{~m}$. The straight impact on the slope is small, which matches the influence of the actual water level component divided from the comprehensive displacement. Therefore, an indirect water level factor, the seepage water pressure, should be the main factor influencing the rock slope along with the geological structure and other factors when compared with the other influencing factors to actual monitoring results. The conclusion was consistent with previous summary. It was also proved that the numerical result matched the actual situation. And it was reasonable.

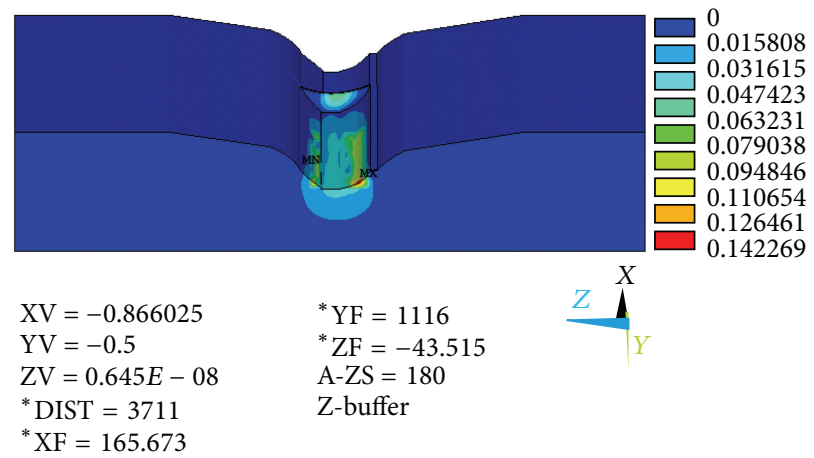

FIGURE 14: Nephogram of the equivalent stress.

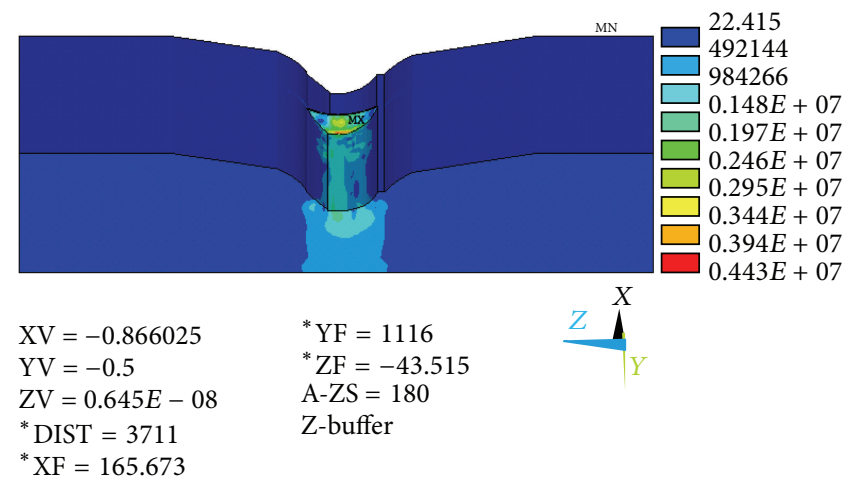

FIGURE 15: Nephogram of the equivalent displacement.

\section{Conclusions}

A comprehensive system of the slope engineering including analysis, calculation, explanation, and conclusion was developed in this study. The deformation of a slope was a combined result of multiple-factor influences in multiple scales. In this study, water level factor was separately extracted and fully analyzed through the actual monitoring analysis. The details of monitoring arrangements and equipment, practical geological model, and rock mechanic parameters were listed. The bottom larger displacement caused by the water erosion and the middle larger displacement formed by the seepage were concluded. The conclusion was based on temporal and spatial displacements rule study of multiple-points linkage effects with water factor based on the complexity and multiple-factor characteristic of the slope. 
To prove the conclusion and explore the influence rule further, three-dimensional finite element model was adopted. To be consistent with previous actual monitoring analysis, the typical cross section of QC10 was extracted. Firstly, the plasticity area and displacement region were calculated by using the DP3 of the D-P criterion. The calculation results were reasonable when compared to the measured results. A program for automatically predicting the strength reduction coefficient was developed using the APDL with the strength reduction method. The typical section of point QC10 was analyzed by this method, and the safety coefficient was 1.248. A general three-dimensional finite element model covering the slope and dam was developed. The influence of the water level was separately analyzed using single water pressure acting on the slope and dam. The straight impact on the slope is small, which matches the result of the actual water level component of the comprehensive displacement. An indirect water level factor, seepage water pressure, is speculated to be the main factor. The analysis results matched the actual situation and are reasonable.

\section{Conflict of Interests}

The authors declare that there is no conflict of interests regarding the publication of this paper.

\section{Acknowledgments}

This research has been partially supported by Jiangsu Natural Science Foundation (Grant no. BK2012036), National Natural Science Foundation of China (Grant nos. 51579083, 51139001, and 41323001), the Specialized Research Fund for the Doctoral Program of Higher Education of China (Grant no. 20130094110010), and the Fundamental Research Funds for the Central Universities (Grant no. 2015B25414).

\section{References}

[1] B. Akpinar, "Online system for monitoring the safety of engineering structures," Tehnicki Vjesnik-Technical Gazette, vol. 22, no. 1, pp. 217-225, 2015.

[2] P. Lollino, F. Santaloia, A. Amorosi, and F. Cotecchia, "Delayed failure of quarry slopes in stiff clays: the case of the Lucera landslide," Geotechnique, vol. 61, no. 10, pp. 861-874, 2011.

[3] A. Ferretti, A. Messori, and S. M. Bergström, "Composition and significance of the katian (Upper Ordovician) conodont fauna of the vaux limestone ('Calcaire des Vaux') in Normandy, France," Estonian Journal of Earth Sciences, vol. 64, no. 3, pp. 214-219, 2014.

[4] D. V. Griffiths and C. O. Li, "Analysis of delayed failure in sloping excavations," Journal of Geotechnical Engineering-ASCE, vol. 119, no. 9, pp. 1360-1378, 1993.

[5] R. Babapour, R. Naghdi, I. Ghajar, and R. Ghodsi, "Modeling the proportion of cut slopes rock on forest roads using artificial neural network and ordinal linear regression," Environmental Monitoring and Assessment, vol. 187, no. 7, article 446, 2015.

[6] J. A. Abdalla, M. F. Attom, and R. Hawileh, "Prediction of minimum factor of safety against slope failure in clayey soils using artificial neural network," Environmental Earth Sciences, vol. 73, no. 9, pp. 5463-5477, 2015.
[7] M. Zevallos and L. K. Hotta, "Slope influence diagnostics in conditional heteroscedastic time series models," Brazilian Journal of Probability and Statistics, vol. 29, no. 1, pp. 34-52, 2015.

[8] S. Vinoth, L. A. Kumar, and E. Kumar, "Slope stability monitoring by quantification and behavior of microseismic events in an opencast coal mine," Journal of the Geological Society of India, vol. 85, no. 4, pp. 450-456, 2015.

[9] K.-T. Chang, L. Ge, and H.-H. Lin, "Slope creep behavior: observations and simulations," Environmental Earth Sciences, vol. 73, no. 1, pp. 275-287, 2014.

[10] S. Alemdag, A. Kaya, M. Karadag, Z. Gurocak, and F. Bulut, "Utilization of the limit equilibrium and finite element methods for the stability analysis of the slope debris: an example of the Kalebasi District (NE Turkey)," Journal of African Earth Sciences, vol. 106, pp. 134-146, 2015.

[11] G. Vasilev, S. Parvanova, P. Dineva, and F. Wuttke, "Soilstructure interaction using BEM-FEM coupling through ANSYS software package," Soil Dynamics and Earthquake Engineering, vol. 70, pp. 104-117, 2015.

[12] R. E. Goodman and D. S. Kieffer, "Behavior of rock in slopes," Journal of Geotechnical and Geoenvironmental Engineering, vol. 126, no. 8, pp. 675-684, 2000.

[13] M. Peng, X. Y. Li, D. Q. Li, S. H. Jiang, and L. M. Zhang, "Slope safety evaluation by integrating multi-source monitoring information," Structural Safety, vol. 49, pp. 65-74, 2014.

[14] H. Rott, B. Scheuchl, A. Siegel, and B. Grasemann, "Monitoring very slow slope movements by means of SAR interferometry: a case study from a mass waste above a reservoir in the Otztal Alps, Austria," Geophysical Research Letters, vol. 26, no. 11, pp. $1629-1632,1999$.

[15] M. S. Morse, N. Lu, A. Wayllace, J. W. Godt, and W. A. Take, "Experimental test of theory for the stability of partially saturated vertical cut slopes," Journal of Geotechnical and Geoenvironmental Engineering, vol. 140, no. 9, Article ID 04014050, 2014.

[16] H. B. Zhao, Z. L. Ru, and S. D. Yin, "A practical indirect back analysis approach for geomechanical parameters identification," Marine Georesources and Geotechnology, vol. 33, no. 3, pp. 212221, 2015.

[17] X. Z. Wu, "Development of fragility functions for slope instability analysis: fragility functions for slope instability analysis," Landslides, vol. 12, no. 1, pp. 165-175, 2015.

[18] H. Z. Su, J. Y. Li, J. P. Cao, and Z. Wen, "Macro-comprehensive evaluation method of high rock slope stability in hydropower projects," Stochastic Environmental Research and Risk Assessment, vol. 28, no. 2, pp. 213-224, 2014.

[19] A. Ardakani, M. Bayat, and M. Javanmard, "Numerical modeling of soil nail walls considering Mohr Coulomb, hardening soil and hardening soil with small-strain stiffness effect models," Geomechanics and Engineering, vol. 6, no. 4, pp. 391-401, 2014.

[20] H. Z. Su, J. Hu, J. Y. Li, and Z. R. Wu, "Deep stability evaluation of high-gravity dam under combining action of powerhouse and dam," International Journal of Geomechanics, vol. 13, no. 3, pp. 257-272, 2013.

[21] Z. Z. Yin, Earthwork Principle, China Water Conservancy and Hydropower Press, Beijing, China, 2007.

[22] K. Zhang, P. Cao, J. J. Meng, K. Li, and W. Fan, "Modeling the a progressive failure of jointed rock slope uusing fracture mechanics and the strength reduction method," Rock Mechanics and Rock Engineering, vol. 48, no. 2, pp. 771-785, 2015.

[23] D. V. Griffiths and P. A. Lane, "Slope stability analysis by finite elements," Geotechnique, vol. 49, no. 3, pp. 387-403, 1999. 
[24] Y. R. Zheng, Z. H. Chen, G. X. Wang, and T. Q. Lin, The Slope and Landslide Engineering Management, China Communication Press, Beijing, China, 2007.

[25] B. Y. Bejarbaneh, D. J. Armaghani, and M. F. M. Amin, "Strength characterisation of shale using Mohr-Coulomb and HoekBrown criteria," Measurement, vol. 63, pp. 269-281, 2015.

[26] J. R. Stianson, D. Chan, and D. G. Fredlund, "Role of admissibility criteria in limit equilibrium slope stability methods based on finite element stresses," Computers and Geotechnics, vol. 48, no. 2, pp. 771-785, 2015.

[27] A. Morales-Esteban, J. L. de Justo, J. Reyes, J. M. Azañón, P. Durand, and F. Martínez-Álvarez, "Stability analysis of a slope subject to real accelerograms by finite elements. Application to San Pedro cliff at the Alhambra in Granada," Soil Dynamics and Earthquake Engineering, vol. 69, pp. 28-45, 2015. 


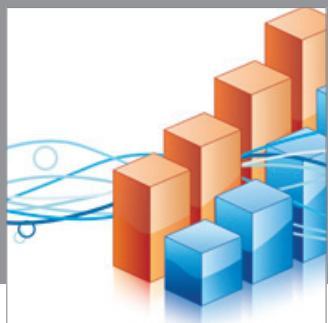

Advances in

Operations Research

mansans

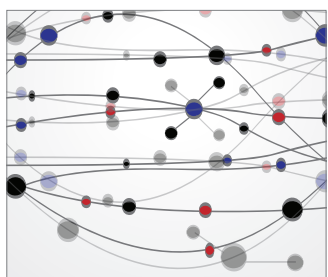

The Scientific World Journal
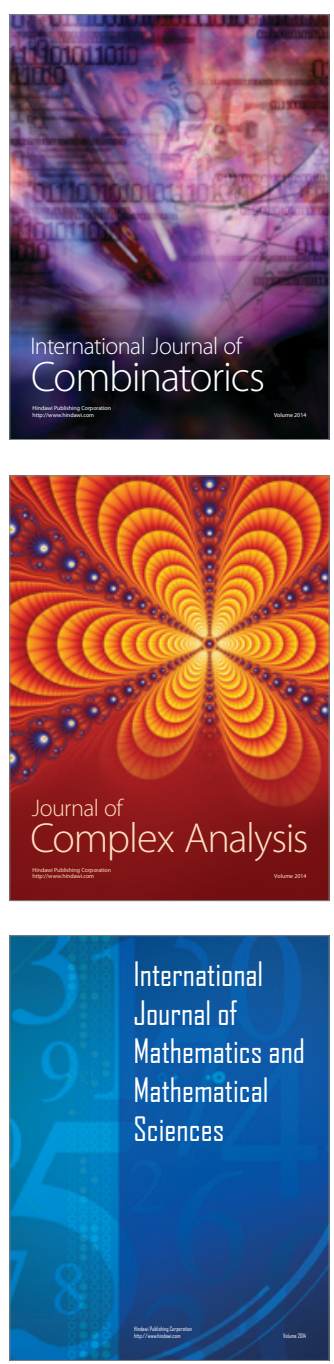
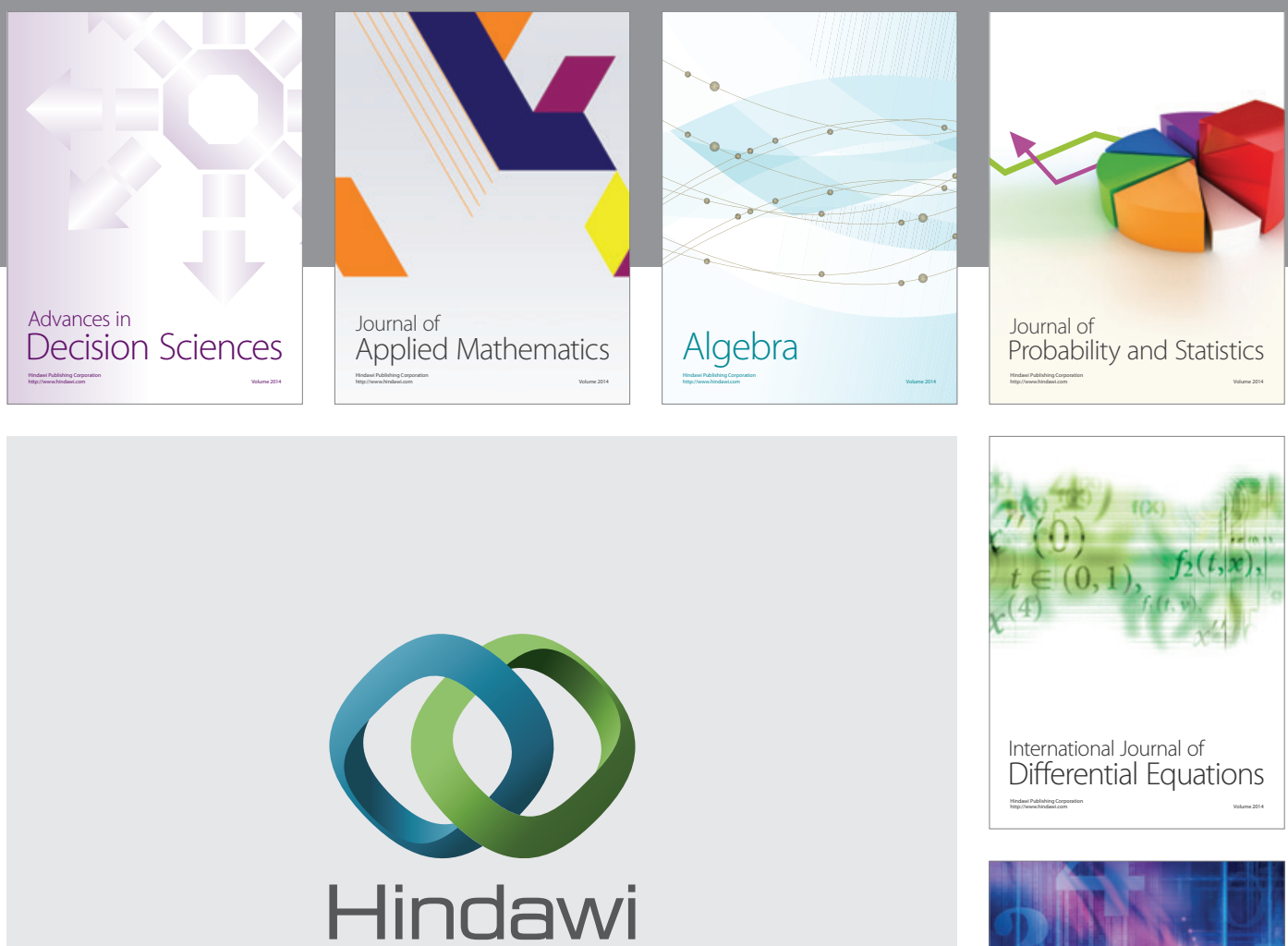

Submit your manuscripts at http://www.hindawi.com
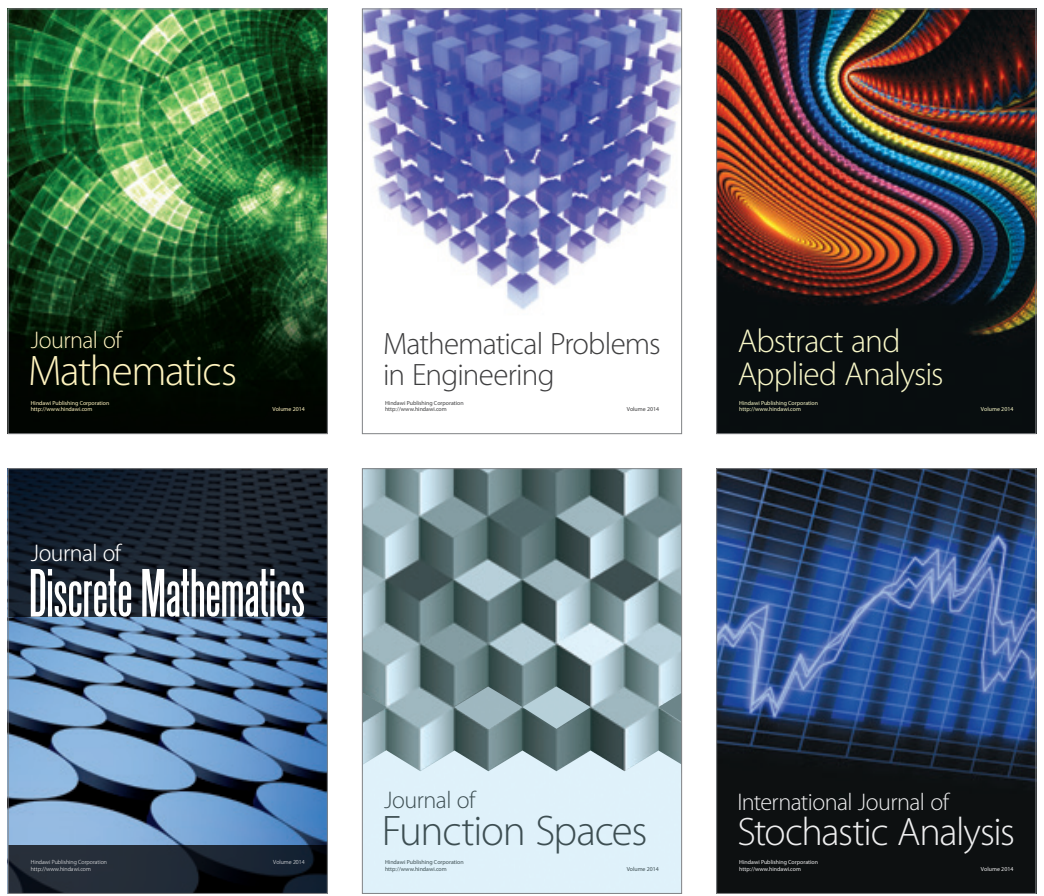

Journal of

Function Spaces

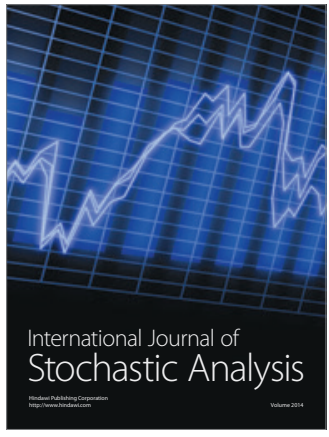

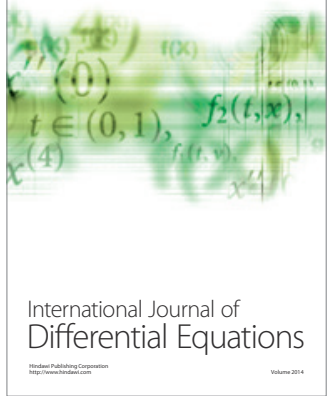
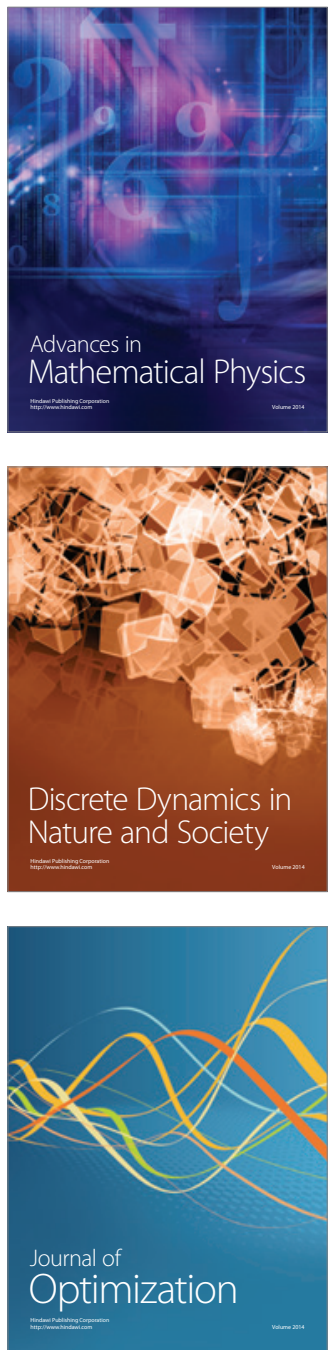